\title{
A Coorelation Study between ABO blood Group and Type 2 Diabetes Mellitus
}

\author{
Dr. Dev Kishan Devra ${ }^{1 *}$, Soniya Pipliwal M.SC ${ }^{2}$, Jyoti Dwivedi M.Sc ${ }^{3}$, Simran M.Sc ${ }^{4}$, Kanta Kumari M.Sc ${ }^{5}$, Dr. Sundar \\ Lal M.D ${ }^{6}$ \\ ${ }^{1}$ associate Professor Department of Phsiology S.P.Medical College Bikaner Rajasthan India \\ ${ }^{2-6}$ Physiology Department of Phsiology S.P.Medical College Bikaner Rajasthan India
}

DOI: 10.36348 /SIJAP.2019.v02i10.002 $\quad$ | Received: 05.10.2019| Accepted: $13.10 .2019 \mid$ Published: 17.10 .2019

*Corresponding author: Dr. Dev Kishan Devra

\section{Abstract}

Introduction: Type 2 diabetes mellitus (T2DM) is inherited genetically. There may be an association with blood group as blood group is predetermined genetically. Methods: Two hundred and thirty one (231) diabetic patients are included in the study which conducted by department of physiology. Diabetic patients were taken from medicine department, and the distribution of blood group among apparently healthy blood donors at Department of Immunohematology and Blood Transfusion (IHBT) was taken as control population. Results: Our study showed no statistically significant association of T2DM with blood group ( $\mathrm{p}$-value=0.81). The percentages of blood group $\mathrm{O}, \mathrm{A}, \mathrm{B}$ and $\mathrm{AB}$ in T2DM and control are respectively $(31.16 \% \& 34 \%)(30.73 \% \& 32 \%),(25.10 \% \& 23 \%)$ and $(12.98 \% \& 9 \%)$.Conclusion: The present study showed no significant association of ABO blood groups with T2DM.

Keywords: ABO Blood group, Association, T2DM.

Copyright @ 2019: This is an open-access article distributed under the terms of the Creative Commons Attribution license which permits unrestricted use, distribution, and reproduction in any medium for non-commercial use (NonCommercial, or CC-BY-NC) provided the original author and source are credited.

\section{INTRODUCTION}

Worldwide the prevalence of diabetes mellitus is increasing speedily and is attaining epidemic magnitude $[1,2]$. Currently the prevalence of T2DM is estimated to be around 285 million and it is assume to grow to 438 million by 2030[3]. Younger adults in economically productive age groups of developing countries are the main section to be affected [4]. Diabetes leads to significant morbidity and premature death in large number afflicted of person affected. Life style changes in the form of dietary modification and regular exercise have shown to be effective tool to prevent development of diabetes in high risk populations $[5,6]$. Individuals belonging to certain blood groups have shown predisposition for certain diseases. Gastric cancer is commoner among individuals with A blood group [7], but gastric and duodenal ulcers is commoner among individuals with $\mathrm{O}$ blood group[8]. Familial predisposition of T2DM is reported to range between $30 \%$ and 70\%[9]. Genetic background thus has a role in the pathogenesis of type 2 diabetes mellitus, although environmental factors playing a big role in the final outcome [10]. Blood group of an individual is genetically predetermined and therefore may have an association with genetically predisposed disease like diabetes mellitus. There are reports of increased prevalence of diabetes in persons belonging to particular blood groups, but no clear conclusion can be drowned with some studies reporting that individuals with certain blood group are more likely to be diabetic but some others studies refuting it. If the increased prevalence with a particular $\mathrm{ABO}$ phenotype is confirmed, preventive strategies can be adopted in those persons. Our study was therefore undertaken considering these conflicting findings.

\section{MATERIAL AND METHODS}

This study conducted by department of physiology. The diabetic patients in this study were recruited from medicine OPD S. P. Medical College Bikaner. Any patient with Type 2 diabetes who gave informed consent was recruited. Individuals were considered to be diabetic if they fulfilled American Diabetes Association cut-off or those patients already on glucose lowering medication. Thorough physical examination and routine blood test was performed as per standard guidelines for diabetic patients. Blood sample was collected for $\mathrm{ABO}$ grouping and $\mathrm{Rh}$ typing. Distribution of blood group among apparently healthy blood donors at Department of Immunohematology and Blood Transfusion (IHBT) was taken as background 
population blood group distribution (control population).

\section{RESULTS}

In the present study two hundred and thirty one (231) type 2 diabetic patients were recruited, out of which, 93 were females and 138 males. The median age of the diabetics was 50 years (range 20-70 years). The comparison of $\mathrm{ABO}$ blood group between type 2 diabetic and healthy controls is shown in table-1. Data collected for T2DM as well as controls are expressed as percentage and analyzed using SPSS version 22.
Comparison between diabetics and healthy controls was done using Chi-Square test to find out whether diabetic patients had a predisposition to certain blood group. $\mathrm{P}$ value $<0.05$ was considered significant. In our study, there was no predilection of any particular ABO blood group with T2DM. Among the diabetic O blood group constituted $(31.16 \%)$ followed by A blood group $(30.73 \%)$, B blood group (25.10\%) and AB blood group $(12.98 \%)$ among patients with T2DM (Table). Similarly, among healthy controls, blood group $\mathrm{O}$ was the most prevalent $(33.4 \%)$, followed by group a (32\%), $\mathrm{B}$ blood group (26\%) and AB blood group (8.3\%).

Table-1: Comparative distribution of $\mathrm{ABO}$ blood group between type 2 diabetic and healthy controls

\begin{tabular}{|l|l|l|l|l|}
\hline BLOOD GROUP & CONTROL & DIABETIC & CHI SQUARE & P VALUE \\
\hline A & 96 & 71 & \multirow{2}{*}{3.06} & \multirow{2}{*}{0.38} \\
\cline { 1 - 2 } B & 79 & 58 & & \\
\cline { 1 - 2 } OB & 25 & 30 & & \\
\cline { 1 - 3 } TOTAL & 100 & 72 & \\
\cline { 1 - 2 } & 300 & 231 & \\
\hline
\end{tabular}

\section{DISCUSSION}

In our present study When blood groups is statistically analyzed among 231 T2DM and 300 voluntary blood donors (controls) statistically significant association is not found. Among T2DM patient blood group $\mathrm{O}$ constitute $31.16 \%$ blood group a $30.73 \%$, blood group B $25.10 \%$ and blood group AB $12.98 \%$. Among control group blood group O constitute $33.4 \%$ blood group A 32\%, blood group B $26 \%$ and blood group AB $8.3 \%$ Similar to our study non association of blood group and T2DM was found by Rahman and Koley[12,13]. Similarly others studies also reported non association of blood group and T2DM [14-16]. On the contrary.

McConnell showed in male diabetic patient frequency of a blood group was more [17]. Meo et al. reported a higher prevalence of T2DM among individuals with B blood group and lowest prevalence amongst $\mathrm{O}$ blood group. Incidence of diabetes was similar among $\mathrm{A}$ and $\mathrm{AB}$ blood groups. There was no difference in the prevalence of T2DM between $\mathrm{Rh}+\mathrm{ve}$ and $\mathrm{Rh}$-ve blood individuals [18]. However, Kamil et $a l$. reported a lower prevalence of T2DM among those whose ABO blood groups are A and O [19]. Forouzan et al. had shown negative correlation between blood group and Type 2 DM [20]. Craig et al. found no significant higher distribution of any particular blood among T2DM compared to non-diabetics [21]. A study by Andersen et al found a significantly higher number of individuals with $\mathrm{O}$ blood group among T2DM male compared with controls; there was an insignificant excess of O blood group among the females [22]. Study by Fagherazzi et al. observed that blood groups A or B were at higher risk of T2DM compared with those with $\mathrm{O}$ blood group. There was no association with the AB group. There was no difference in type 2 diabetes mellitus risk between Rhesus positive and negative groups [23]. Qureshi and Bhatti demonstrated an interrelationship between that T2DM and ABO blood groups. Among patients with T2DM, blood group B was commoner compared to the non-diabetics, but this was not statistically significant. There was a statistically insignificant higher percentage of $\mathrm{O}$ and $\mathrm{A}$ blood groups among healthy controls compared to patients with T2DM [24]. Jolly and Sarup et al. found significantly higher percentage of group $\mathrm{O}$ among diabetic patient [25]. Again Jassim found significantly higher occurrence of blood group $\mathrm{O}$ than other groups among T2DM patients compared to controls [26]. Waseem et al. showed a lower percentage of blood groups A and B among T2DM patients compared to controls, however, the percentage of blood group $\mathrm{AB}$ was higher among diabetics compared to controls [27].

\section{CONCLUSION}

Our study could not find association of blood group with T2DM. This in contrast to some studies which have shown a higher percentage of certain $\mathrm{ABO}$ blood groups with T2DM. The difference in the result from these studies may be due to ethnic background of our study sample.

\section{REFERENCES}

1. International Diabetes Federation.(2015). IDF Diabetes Atlas, seventh edition 2015. [http://www.idf.org/ idf-diabetes-atlasseventhedition 2015. [Last cited on 2017 September 1]

2. Zimmet, P. Z. (1992). Kelly West Lecture 1991 challenges in diabetes epidemiology-from West to the rest. Diabetes care, 15(2), 232-252.

3. Dowse, G. K., Gareeboo, H., Zimmet, P. Z., Alberti, K. G. M., Tuomilehto, J., Fareed, D., ... \& Mauritius Noncommunicable Disease Study Group. (1990). High prevalence of NIDDM and 
impaired glucose tolerance in Indian, Creole, and Chinese Mauritians. Diabetes, 39(3), 390-396.

4. Zimmet, P., Taylor, R., Ram, P., King, H., Sloman, G., Raper, L. R., \& Hunt, D. (1983). Prevalence of diabetes and impaired glucose tolerance in the biracial (Melanesian and Indian) population of Fiji: a rural-urban comparison. American journal of epidemiology, 118(5), 673-688.

5. Knowler, W. C., Barrett-Connor, E., Fowler, S. E., Hamman, R. F., Lachin, J. M., Walker, E. A., \& Nathan, D. M. (2002). Reduction in the incidence of type 2 diabetes with lifestyle intervention or metformin. The New England journal of medicine, 346(6), 393-403.

6. Chiasson, J. L., Josse, R. G., Gomis, R., Hanefeld, M., Karasik, A., Laakso, M., \& STOP-NIDDM Trial Research Group. (2002). Acarbose for prevention of type 2 diabetes mellitus: the STOPNIDDM randomised trial. The Lancet, 359(9323), 2072-2077.

7. Aird, I., Bentall, H. H., \& Roberts, J. F. (1953). Relationship between cancer of stomach and the ABO blood groups. British medical journal, 1(4814), 799.

8. Clarke, C. A., Cowan, W. K., Edwards, J. W., Howel-Evans, A. W., McConnell, R. B., Woodrow, J. C., \& Sheppard, P. M. (1955). The relationship of the ABO blood groups to duodenal and gastric ulceration. British medical journal, 2(4940), 643.

9. Newman, B., Selby, J. V., King, M. C., Slemenda, C., Fabsitz, R., \& Friedman, G. D. (1987). Concordance for type 2 (non-insulin-dependent) diabetes mellitus in male twins. Diabetologia, 30(10), 763-768.

10. Eff, C., Leslie, R. D. G., Pyke, D. A., \& Bamett, A. H. (1981). Diabetes in identical twins. A study of 200 pairs. Diabetologia, 20, 87-93.

11. American Diabetes Association. (2013). Diagnosis and classification of diabetes mellitus. Diabetes care, 36(Supplement 1), S67-S74.

12. Rahman, M. (1976). Non-association of ABO blood groups with diabetes mellitus in Bangladesh. Bangladesh Medical Research Council bulletin, 2(2), 144-146.

13. Koley, S. (2008). The distribution of the ABO blood types in patients with diabetes mellitus. The Anthropologist, 10(2), 129-132.

14. Meo, S. A., Rouq, F. A., Suraya, F., \& Zaidi, S. Z. (2016). Association of ABO and Rh blood groups with type 2 diabetes mellitus. Eur Rev Med Pharmacol Sci, 20(2), 237-42.
15. Sharma, S., Kumar, J., Choudhary, R., \& Soni, N. D. (2014). Study of Association between ABO Blood Groups and Diabetes Mellitus. Sch J App Med Sci, 2(1A), 34-37.

16. Dali, S. M., Aour, M. A., Belmokhtar, F., Belmokhtar, R., \& Boazza, F. (2011). The relationship between $\mathrm{ABO} /$ rhesus blood groups and type 2 diabetes mellitus in Maghnia, western Algeria. South African Family Practice, 53(6), 568-572.

17. McConnell, R. B., Pyke, D. A., \& Roberts, J. F. (1956). Blood groups in diabetes mellitus. British medical journal, 1(4970), 772.

18. Meo, S. A., Rouq, F. A., Suraya, F., \& Zaidi, S. Z. (2016). Association of ABO and Rh blood groups with type 2 diabetes mellitus. Eur Rev Med Pharmacol Sci, 20(2), 237-42.

19. Kamil, M., Ali Nagi Al-Jamal, H., \& Mohd Yusoff, N. (2010). Association of ABO blood groups with diabetes mellitus. Libyan Journal of Medicine, 5(1), 4847.

20. Moinzadeh, F., Najafabady, G. M., \& Toghiani, A. (2014). Type 2 diabetes mellitus and $\mathrm{ABO} / \mathrm{Rh}$ blood groups. Journal of research in medical sciences: the official journal of Isfahan University of Medical Sciences, 19(4), 382.

21. Craig, J., \& Wang, I. (1955). Blood groups in diabetes mellitus. Glasgow medical journal, 36(8), 261.

22. Andersen, J., \& Lauritzen, E. (1960). Blood groups and diabetes mellitus. Diabetes, 9(1), 20-24.

23. Fagherazzi, G., Gusto, G., Clavel-Chapelon, F., Balkau, B., \& Bonnet, F. (2015). ABO and Rhesus blood groups and risk of type 2 diabetes: evidence from the large E3N cohort study. Diabetologia, 58(3), 519-522.

24. Qureshi, M. A., \& Bhatti, R. (2003). Frequency of ABO blood groups among the diabetes mellitus type 2 patients. Journal of the College of Physicians and Surgeons--Pakistan: JCPSP, 13(8), 453-455.

25. Jolly, J. G., Sarup, B. M., \& Aikat, B. K. (1969). Diabetes mellitus and blood groups. Journal of the Indian Medical Association, 52(3), 104-107.

26. Jassim, W. E. (2012). Association of ABO blood group in Iraqis with hypercholesterolaemia, hypertension and diabetes mellitus.

27. Waseem, A. G., Iqbal, M., Khan, O. A., \& Tahir, M. (2012). Association of diabetes mellitus with $\mathrm{ABO}$ and Rh blood groups. Ann Pak Inst Med Sci, 8(2), 134-6. 